\title{
SEMENTES DE FEIJÃO SUBMETIDAS A CICLOS E PERÍODOS DE HIDRATAÇÃO-SECAGEM
}

\author{
Carlos Alberto Aragão ${ }^{1,2 *}$; Bárbara França Dantas ${ }^{1,2}$; Elza Alves ${ }^{1,2}$; Marcelo Rocha Corrêa1,3 \\ ${ }^{1}$ Depto. de Produção Vegetal - Setor Agricultura e Melhoramento Vegetal - FCA/UNESP, C.P. 237 - CEP: $18603-970$ - \\ Botucatu, SP. \\ ${ }^{2}$ Bolsista CAPES. \\ Bolsista CNPq \\ *Autor correspondente <caaragao@fca.unesp.br>
}

RESUMO: A técnica de hidratação-secagem pode ocasionar alterações fisiológicas e bioquímicas em sementes de feijão e afetar sua qualidade fisiológica. Sementes do cultivar Carioca foram submetidas a tratamentos de hidratação-secagem por 6, 12 e 24 horas com três ciclos de hidratação, com o objetivo de avaliar os efeitos causados por períodos e ciclos de hidratação-secagem na qualidade fisiológica das sementes. O delineamento experimental utilizado foi inteiramente casualizado, com quatro repetições, analisado estatisticamente em esquema fatorial $3 \times 3$ com uma testemunha absoluta. Para a primeira contagem da germinação, os tratamentos de períodos combinados com ciclos de hidratação-secagem, apresentaram superioridade em relação ao tratamento testemunha. Na avaliação de grupos de proteínas, as concentrações de globulinas e prolaminas nas sementes submetidas aos tratamentos, foram significativamene superiores a testemunha. Os cátions ( $\mathrm{Ca}, \mathrm{Mg}$ e K) lixiviados para solução de embebição das sementes tiveram comportamento semelhante à condutividade elétrica das mesmas.

Palavras-chave: condicionamento fisiológico, sementes, proteínas

\section{BEAN SEEDS SUBJECTED TO HYDRATION-DEHYDRATION CYCLES AND PERIODS}

\begin{abstract}
The hydration-dehydration technique may cause physiological and biochemical modifications in bean seeds, affecting their physiological quality. Seeds cv. Carioca were submitted to hydration-dehydration treatments for 6, 12 and 24 hours with three hydration cycles. The objective was evaluate the effects caused by hydration-dehydration treatments on bean seed physiological quality. The experimental design was completely randomized, with four replications, $3 \times 3$ factorial, with an absolute control. At the first germination count the hydration-dehydration duration and cycle treatments were superior in relation to the control. Regarding the protein fractions the treated seed globulin and prolamin concentrations increased significantly as compared to the controls. The leached cations $(\mathrm{Ca}, \mathrm{Mg}$ and $\mathrm{K})$ in the seed imbibition solution had a similar behaviour in relation to the electrolytic leakage.
\end{abstract}

Key words: priming, seeds, protein

\section{INTRODUÇÃO}

As sementes do feijoeiro (Phaseolus vulgaris), como a maioria das espécies, suportam armazenamento por períodos curtos. No entanto, o armazenamento prolongado induz uma série de processos degenerativos, devido à migração de água do ambiente para as sementes, aumentando o teor de água das sementes que, combinado com elevadas temperaturas constituem os fatores principais para o progresso da deterioração.

Dependendo das condições climáticas, as sementes podem vir a ganhar ou perder água facilmente e, neste processo de hidratação-secagem geralmente ocorrem danos ao tegumento e, como conseqüência, redução da qualidade fisiológica. Sob hidratação parcial durante o período de pré-colheita (Motta \& Silva, 1997) ou após a semeadura em solos de baixo potencial hídrico (Hegarty, 1977), podem ocorrer alterações fisiológicas prejudiciais. Quando as sementes ficam expostas às oscilações de umidade do solo, levando a vários ciclos de hidratação e secagem, a germinação pode ser afetada (Berrie \& Drennan, 1971; Hegarty, 1978). Williams (1980) demonstrou que quanto maior o número de ciclos de hidratação-secagem a que as sementes são submetidas, maior será a redução da germinação e estes efeitos deletérios aumentam com o período de hidratação.

Por outro lado, Rudrapal \& Nakamura (1988) constataram que sementes de beringela e rabanete submetidas a tratamentos de hidratação por 24 e 72 horas seguidos de secagem imediata, exibiram menor perda de vigor e de viabilidade que sementes não tratadas. Este benefício foi atribuído à menor lixiviação de açúcares, maior atividade de enzimas desidrogenases além de menor peroxidação de lipídios, com conseqüente redução de danos aos componentes celulares das sementes, provocados por radicais livres.

Segundo Heydecker et al. (1975), a hidratação e secagem de sementes, antes da semeadura, tem se mostrado semelhante aos processos de condicionamento osmótico, onde as sementes, em uma solução de 
potencial osmótico conhecido, absorvem água até um nível que permita a ativação de todos os eventos metabólicos essenciais à germinação, sem atingir a fase de alongamento celular. Peñaloza \& Eira (1993), descrevem a técnica de hidratação-secagem como uma alternativa viável para a melhoria de qualidade fisiológica de lotes de sementes de tomate com médio vigor.

Pelo exposto, fica evidenciada a necessidade de serem desenvolvidos trabalhos nessa linha de pesquisa com outras espécies, no sentido de elucidar efeitos causados pelo processo de hidratação-secagem em sementes.

Desta forma, este trabalho teve como objetivo avaliar alterações fisiológicas e bioquímicas em sementes de feijão, submetidas a ciclos de hidrataçãosecagem.

\section{MATERIAL E MÉTODOS}

O experimento foi realizado nos Laboratórios de Análise de Sementes e Relação-Solo-Planta do Departamento de Produção Vegetal/Setor de Agricultura e Melhoramento Vegetal da Faculdade de Ciências Agronômicas da Universidade Estadual Paulista (UNESP), Botucatu-SP, nos meses de janeiro a maio de 2000.

Sementes de feijão do cultivar Carioca, retidas em peneira de crivos circulares de 12/64" (4,76 mm), foram colocadas para hidratar, durante 6, 12 e 24 horas, em micro ambiente úmido desenvolvido em caixas de germinação (gerbox) adaptadas para teste de envelhecimento acelerado, em temperatura ambiente $\left(25^{\circ} \mathrm{C}\right)$, seguidas de secagem realizada em câmara seca $(40 \%$ UR) para retorná-las ao grau de umidade inicial da testemunha de $(11,4 \%)$. Após este tratamento, dividiu-se cada uma das amostras $(6,12$ e 24 horas de hidratação-secagem), em três subamostras. Uma das subamostras (com apenas um ciclo de hidratação/ secagem) de cada amostra, foi armazenada em frascos de vidro em germinador a $10^{\circ} \mathrm{C}$. As demais subamostras foram submetidas a dois e três ciclos de hidratação, seguidos de secagem, até retornarem novamente à umidade inicial das sementes e armazenadas a $10^{\circ} \mathrm{C}$, conforme mencionado. Este procedimento permitiu obter três lotes distintos quanto ao número de ciclos de hidratação, para cada período de hidratação-secagem, totalizando-se nove tratamentos. Para avaliar os efeitos dos tratamentos sobre a qualidade das sementes, empregou-se uma testemunha, constituída das sementes nas condições iniciais, anteriormente descritas.

Após a aplicação dos tratamentos, as sementes previamente tratadas com Captan, foram submetidas a teste de germinação em laboratório, conduzido com quatro subamostras de 50 sementes, distribuídas em rolo de papel germitest umedecido com quantidade de água equivalente a 2,5 vezes o peso do substrato e mantidas em germinador a $25^{\circ} \mathrm{C}$ (Brasil, 1992). A germinação foi avaliada aos cinco e nove dias após a semeadura, e os resultados expressos em porcentagem média de plântulas normais.

Parte das sementes submetidas a períodos e ciclos de hidratação-secagem, foi finamente moída para proceder o fracionamento seqüencial das proteínas. As amostras ( $1 \mathrm{~g}$ de material moído) foram colocadas em tubos de ensaio, sendo adicionados $10 \mathrm{~mL}$ do primeiro extrator $\left(\mathrm{H}_{2} \mathrm{O}\right.$ destilada). Após incubação a $25^{\circ} \mathrm{C}$, durante 60 minutos, as amostras foram centrifugadas a $1500 \mathrm{xg}$ durante 10 minutos. O sobrenadante foi, então, coletado e o precipitado ressuspendido com o mesmo volume inicial do mesmo extrator, repetindo por mais duas vezes a incubação, centrifugação e coleta do sobrenadante. Após as três coletas de $10 \mathrm{~mL}$ obteve-se a fração de albuminas. O resíduo da extração da fração albumina foi submetido à extração da fração globulina de forma semelhante utilizando, como extrator, $\mathrm{NaCl}(1 \%)$. O mesmo ocorreu para as extrações de prolamina e glutelina, utilizando os extratores etanol $(70 \%)$ e $\mathrm{NaOH}\left(0,1 \mathrm{~mol} \mathrm{~L}^{-1}\right)$, respectivamente. A quantificação das proteínas foi feita pelo método de Bradford (1976), utilizando $300 \mathrm{~mL}$ dos extratos e 1000 $\mathrm{mL}$ do reagente Comassie Blue G-250. As leituras foram feitas em espectrofotômetro a $595 \mathrm{~nm}$ e comparadas com a curva padrão obtida com concentrações conhecidas de soro-albumina bovina (BSA).

A condutividade elétrica foi determinada utilizando-se quatro subamostras de 25 sementes, as quais foram pesadas e colocadas em um recipiente de $100 \mathrm{~mL}$, com $75 \mathrm{~mL}$ de água destilada e mantidas em câmara a $25^{\circ} \mathrm{C}$ durante 24 horas. Após esse período, foi feita a leitura de exsudatos na solução, com auxílio de condutivímetro, sendo calculada a condutividade em função do peso inicial das sementes utilizadas (Association of Official seed Analysis, 1983). Determinouse também a quantidade dos íons $\left(\mathrm{Ca}^{++}, \mathrm{Mg}^{++}\right.$e $\left.\mathrm{K}^{+}\right)$ liberados pelas sementes, durante a embebição, através de leitura direta de $30 \mathrm{~mL}$ da solução em espectrofotômetro de absorção atômica. Ainda nas soluções de embebição foi determinado o teor de açúcares redutores pela metodologia descrita por Miller (1959), utilizando ácido 3,5 dinitrosalicílico (DNS) para a oxidação desses compostos. A concentração de açúcares redutores foi determinada em espectofotômetro a $540 \mathrm{~nm}$ com base na curva padrão obtida com concentrações conhecidas de glicose.

O delineamento experimental utilizado foi inteiramente casualizado, analisado estatisticamente em esquema fatorial $3 \times 3 \mathrm{com}$ uma testemunha absoluta, com quatro repetições. As médias dos tratamentos foram comparadas pelo teste de Tukey a $5 \%$, sendo a testemunha absoluta comparada com a média geral dos tratamentos. 


\section{RESULTADOS E DISCUSSÃO}

Para germinação, houve comportamento semelhante para todos os tratamentos, não havendo diferenças entre os mesmos (Tabela 1).

A técnica de hidratação-secagem é muito controversa, tendo diferentes resultados dependendo da espécie estudada. Segundo Peñaloza \& Eira (1993), a hidratação-secagem pode ser uma alternativa para a melhoria de qualidade fisiológica de lotes de médio vigor de sementes de tomate. Dias et al. (1996) observaram que a hidratação-secagem em feijão-de-vagem contribuiu para a melhoria da qualidade das sementes, apresentando bom desempenho do seu poder germinativo. Aragão et al. (1999) observaram que o processo de hidração-secagem, contribuiu para o aumento da emergência de plântulas em campo de feijão, do cultivar Bolinha. Por outro lado, Berrie \& Drennan (1971), trabalhando com sementes de aveia e tomate, verificaram que maiores períodos de hidratação associado a ciclos afetaram negativamente a taxa de germinação destas sementes.

A porcentagem de plântulas normais na primeira contagem do teste de germinação (Tabela 2) das sementes submetidas aos tratamentos de períodos e ciclos de hidratação-secagem, foram superiores ao tratamento testemunha (sem hidratação). O efeito observado pode estar associado a uma pré-embebição das sementes durante o processo de hidratacãosecagem, refletindo em maior velocidade de emergência das mesmas. O modo de ação de tratamentos de hidratação-secagem, foi muito estudado por Basu e colaboradores (Basu \& Dasgupta, 1978; Basu \& Rudrapal, 1982; Pan \& Basu, 1985), sendo que uma das hipóteses para explicar os efeitos benéficos do tratamento de hidratação-secagem na semente, pode estar associado ao reparo das membranas durante a fase de hidratação. Desta forma, a perda de íons e açúcares durante a embebição das sementes é inibida (Villiers \& Edgecumbe, 1975).

Em relação à análise dos grupos de proteínas de reserva, observa-se que as sementes submetidas aos ciclos de hidratação-secagem apresentaram diferenças significativas entre a média dos tratamentos e a testemunha apenas para teores de globulina e prolamina, sendo que estes valores foram o dobro dos observados para a testemunha (Tabelas 4 e 5).

Para os teores de albumina (Tabela 3), que foram maiores em relação aos teores das outras proteínas, podese observar que para um ciclo de hidratação, o período de 12 horas induziu uma concentração nas sementes. Com dois e três ciclos de hidratação, os maiores teores de albumina são observados com 24 horas. Em hidratação por 6 horas, as sementes submetidas a um e dois ciclos de hidratação, tiveram maior concentração de albuminas. Fato observado também para 12 horas com um ciclo e, 24 horas com dois e três ciclos de hidratação-secagem.
Segundo Motta \& Silva (1997), quando a semente atinge um nível adequado de hidratação, sendo viável e não dormente, procederá no sentido da germinação plena, reativando o seu metabolismo pela hidratação e ativação de enzimas preexistentes inativas ou indução da síntese de novo de outras enzimas. As albuminas, por serem proteínas solúveis em água, têm natureza enzimática (Mayer \& Poljakoff-Mayber, 1978), o grande aumento dessas proteínas pode indicar um alto metabolismo nas sementes tratadas.

Tabela 1 - Germinação das sementes de feijão nos períodos e ciclos de hidratação.

\begin{tabular}{lccc}
\hline $\begin{array}{l}\text { Período de } \\
\text { hidratação }\end{array}$ & Média & $\begin{array}{c}\text { Ciclo de } \\
\text { hidratação }\end{array}$ & Média \\
\hline & $\%$ & & $\%$ \\
$6 \mathrm{~h}$ & $95 \mathrm{a}$ & 1 & $96 \mathrm{a}$ \\
$12 \mathrm{~h}$ & $95 \mathrm{a}$ & 2 & $95 \mathrm{a}$ \\
$24 \mathrm{~h}$ & $95 \mathrm{a}$ & 3 & $94 \mathrm{a}$ \\
\hline Média geral & 95 & & $95 \alpha$ \\
\hline Test. (absoluta) & & & $93 \alpha$ \\
\hline CV (\%) & 4,01 & & \\
\hline
\end{tabular}

Médias seguidas pela mesma letra não diferem pelo teste de Tukey, a $5 \%$. As letras gregas diferentes indicam diferença a $5 \%$.

Tabela 2 - Primeira contagem da germinação das sementes de feijão nos períodos e ciclos de hidratação.

\begin{tabular}{lccc}
\hline $\begin{array}{l}\text { Período de } \\
\text { hidratação }\end{array}$ & Média & $\begin{array}{c}\text { Ciclo de } \\
\text { hidratação }\end{array}$ & Média \\
\hline & $\%$ & & $\%$ \\
$6 \mathrm{~h}$ & $92 \mathrm{a}$ & 1 & $95 \mathrm{a}$ \\
$12 \mathrm{~h}$ & $93 \mathrm{a}$ & 2 & $91 \mathrm{ab}$ \\
$24 \mathrm{~h}$ & $92 \mathrm{a}$ & 3 & $89 \mathrm{~b}$ \\
\hline Média geral & 92 & & $92 \alpha$ \\
\hline Test. (absoluta) & & & $88 \beta$ \\
\hline CV (\%) & 5,12 & &
\end{tabular}

Médias seguidas pela mesma letra não diferem pelo teste de Tukey, a $5 \%$. As letras gregas diferentes indicam diferença a $5 \%$.

Tabela 3 - Teores de albumina em sementes de feijão nos períodos e ciclos de hidratação.

\begin{tabular}{|c|c|c|c|c|}
\hline \multirow{2}{*}{$\begin{array}{l}\text { Período de } \\
\text { hid ratação }\end{array}$} & \multicolumn{4}{|c|}{ Ciclo de hidratação } \\
\hline & 1 ciclo & 2 ciclo & 3 ciclo & Média \\
\hline & \multicolumn{4}{|c|}{------- $\mathrm{mg} \mathrm{g}^{-1}$ de matéria fresca ----- } \\
\hline $6 \mathrm{~h}$ & $40,52 \mathrm{bA}$ & $42,76 \mathrm{bA}$ & $25,91 \mathrm{bB}$ & 36,40 \\
\hline $12 \mathrm{~h}$ & $47,30 \mathrm{aA}$ & $33,54 \mathrm{cB}$ & $31,11 \mathrm{bB}$ & 37,32 \\
\hline $24 \mathrm{~h}$ & $35,73 \mathrm{bB}$ & 52,16 aA & 47,48 aA & 45,12 \\
\hline Média & 41,18 & 42,82 & 34,83 & $39,61 \alpha$ \\
\hline Test. (absoluta) & & & & $36,11 \alpha$ \\
\hline $\mathrm{CV}(\%)$ & 9,44 & & & \\
\hline
\end{tabular}

Médias seguidas pela mesma letra minúscula na coluna e maiúscula na linha, não diferem pelo teste de Tukey, a $5 \%$. As letras gregas diferentes indicam diferença a $5 \%$. 
Os teores de globulina após um, dois e três ciclos de hidratação-secagem foram maiores com 24 horas de exposição das sementes (Tabela 4). Por outro lado, ao analisar os períodos de hidratação, foi verificado que para 6 horas, dois ciclos promoveram maiores teores de globulina, enquanto que para $12 \mathrm{e}$ 24 horas, os melhores resultados foram observados com um ciclo. O mesmo comportamento pode ser observado para os teores de prolamina (Tabela 5). Em sementes de feijão quiescentes, a fração globulina chega a até $75 \%$ do total de proteínas nas sementes (Ishino \& Ortega, 1975), sendo esta a mais importante proteína de reserva.

Segundo Peñaloza \& Eira (1993), a técnica de hidratação-secagem pode aumentar a qualidade fisiológica de lotes sementes de médio vigor. O processo de hidratação de sementes, seguida de secagem imediata, poderá todavia levar a uma melhoria no desempenho das mesmas, pela redução do período de tempo entre a semeadura e a emergência das plântulas feijão-de-vagem (Dias et al., 1996). A maior extração de globulinas e prolamina, as proteínas de reserva mais importantes, de sementes tratadas em relação às testemunhas pode indicar uma maior disponibilidade à plântula na ocasião da germinação indicando um crescimento mais acelerado e maior vigor de plântulas, conforme observado na Tabela 2.

Com relação aos dados médios de glutelina (Tabela 6), os efeitos de períodos e ciclos de hidratação-secagem foram independentes, não havendo interação para os mesmos. Durante os períodos de 12 e 24 horas de hidratação-secagem, as sementes tiveram comportamento semelhante, diferindo estatisticamente do tratamento de 6 horas de hidratação-secagem. As sementes submetidas a dois e três ciclos apresentaram teores mais altos de glutelina quando comparadas a um ciclo de hidratação.

Após o terceiro ciclo de hidratação-secagem das sementes durante 6 e 24 horas, o vigor das mesmas foi afetado, refletindo na maior lixiviação eletrolítica dos solutos celulares, representados pela condutividade elétrica (Tabela 7 ). Este efeito negativo afetou da mesma forma o tratamento de 24 horas, após um ciclo de hidratação.

A intensidade dos efeitos comentados, deve ter contribuído negativamente para a ocorrência de perfeita ativação do processo de reparo metabólico das sementes, afetando a reorganização dos fosfolipídeos da membrana plasmática (Pearce \& Abdel-Samad, 1980), em função dos sucessivos ciclos de hidratação-secagem das sementes. A média dos tratamentos de hidratação-secagem não diferiu estatisticamente da testemunha (Tabela 7).

Os teores de açúcares redutores dos lixiviados das sementes que receberam os tratamentos de períodos e ciclos de hidratação-secagem, foram de maneira geral, estatisticamente superiores à testemunha (Tabela 8). Esse fato pode ser atribuído à perda de seletividade das membranas celulares das sementes, quando hidratadas por vários ciclos, não interferindo, porém, na condutividade elétrica da solução.

Rudrapal \& Nakamura (1988) verificaram que em sementes de berinjela e rabanete, submetidas ao processo de hidratação-secagem, a lixiviação de açúcares totais, assim como a condutividade elétrica, foi menor em relação a testemunha. Neste experimento foram avaliados apenas os açúcares redutores, glicose e frutose, não havendo quantificação de açúcares totais. Por este motivo, os resultados encontrados não corresponderam aos valores de condutividade elétrica.

Com três ciclos de hidratação das sementes durante 12 e 24 horas, os cátions $\mathrm{Ca}^{++}$e $\mathrm{K}^{+}$foram os mais perdidos para a solução, enquanto que, para o mesmo número de ciclos, o $\mathrm{Mg}^{++}$foi mais lixiviado durante o período de 12 horas de hidratação (Tabela 9). Desta forma constata-se, que 12 e 24 horas, foram os períodos de exposição das sementes a hidratação-secagem, significativamente mais prejudiciais.

A evolução da condutividade elétrica (Tabela 7) segue a marcha de lixiviação dos íons $\mathrm{Ca}^{++}, \mathrm{Mg}^{++} \mathrm{e}$ $\mathrm{K}^{+}$(Tabela 9), e é oposta à lixiviação de acúcares redutores (Tabela 8). A condutividade elétrica sofre influência marcante do número de ciclos e aumento de período de hidratação-secagem das sementes de feijão, pois corresponde ao início da degradação do sistema de membranas das sementes.

Abdel-Samad \& Pearce (1978) constataram rápida liberação de $\mathrm{K}^{+}$e outros compostos na primeira hora de embebição de sementes de amendoim. Perdas de $\mathrm{Ca}^{++}, \mathrm{Mg}^{++}, \mathrm{Mn}^{++}, \mathrm{K}^{+}$e $\mathrm{Cl}^{-}$, durante a embebição de sementes de repolho envelhecidas artificialmente, foram avaliadas por Loomis \& Smith (1980).

Tabela 4 - Teores de globulina em sementes de feijão nos períodos e ciclos de hidratação.

\begin{tabular}{|c|c|c|c|c|}
\hline \multirow{2}{*}{$\begin{array}{l}\text { Período de } \\
\text { hidratação }\end{array}$} & \multicolumn{4}{|c|}{ Ciclo de hidratação } \\
\hline & 1 ciclo & 2 ciclo & 3 ciclo & Média \\
\hline & \multicolumn{4}{|c|}{------ $\mathrm{mg} \mathrm{g}^{-1} \mathrm{de}$ matéria fresca --.-- } \\
\hline $6 \mathrm{~h}$ & $218,2 \mathrm{cB}$ & $428,7 \mathrm{bA}$ & $207,1 \mathrm{bB}$ & 284,6 \\
\hline $12 \mathrm{~h}$ & $541,0 \mathrm{bA}$ & $422,3 \mathrm{bAB}$ & $303,6 \mathrm{bB}$ & 422,3 \\
\hline $24 \mathrm{~h}$ & 868,6 aA & $616,9 \mathrm{aB}$ & $537,8 \mathrm{aB}$ & 674,4 \\
\hline Média & 542,6 & 489,3 & 349,5 & $460,7 \alpha$ \\
\hline Test. (absoluta) & & & & $224,5 \beta$ \\
\hline $\mathrm{CV}(\%)$ & 20,41 & & & \\
\hline
\end{tabular}

Médias seguidas pela mesma letra minúscula na coluna e maiúscula na linha, não diferem pelo teste de Tukey, a 5\%. As letras gregas diferentes indicam diferença a $5 \%$. 
Tabela 5 - Teores de prolamina em sementes de feijão nos períodos e ciclos de hidratação.

\begin{tabular}{lllll}
\hline \multirow{2}{*}{$\begin{array}{l}\text { Período de } \\
\text { hidratação }\end{array}$} & \multicolumn{4}{c}{ Ciclo de hidratação } \\
\cline { 2 - 5 } & 1 ciclo & \multicolumn{4}{c}{ 2ciclos } & 3ciclos & Média \\
\hline 6h & $218,2 \mathrm{cB}$ & $428,7 \mathrm{bA}$ & $207,1 \mathrm{bB}$ & 284,6 \\
$12 \mathrm{~h}$ & $496,7 \mathrm{bA}$ & $422,3 \mathrm{bA}$ & $303,6 \mathrm{bB}$ & 407,5 \\
$24 \mathrm{~h}$ & $937,7 \mathrm{aA}$ & $616,9 \mathrm{aB}$ & $593,8 \mathrm{aB}$ & 716,1 \\
\hline Média & 550,8 & 489,3 & 368,2 & $469,4 \alpha$ \\
\hline Test. (absoluta) & & & & $224,1 \beta$ \\
\hline CV (\%) & 14,22 & & & \\
\hline
\end{tabular}

Médias seguidas pela mesma letra minúscula na coluna e maiúscula na linha, não diferem pelo teste de Tukey, a $5 \%$. As letras gregas diferentes indicam diferença a $5 \%$.

Tabela 6 - Teores de glutelina em sementes de feijão nos diferentes períodos e ciclos de hidratação.

\begin{tabular}{lccc}
\hline Período de & \multicolumn{3}{c}{ Ciclo de } \\
\cline { 2 - 4 } hidratação $(\mathrm{h})$ & Média & hidratação & Média \\
\hline & $\mathrm{mg} \mathrm{g}^{-1}$ & & $\mathrm{mg} \mathrm{g}^{-1}$ \\
\hline $\mathrm{h}$ & $597,8 \mathrm{~b}$ & 1 & $617,0 \mathrm{~b}$ \\
$12 \mathrm{~h}$ & $1096,3 \mathrm{a}$ & 2 & $1051,3 \mathrm{a}$ \\
$24 \mathrm{~h}$ & $991,8 \mathrm{a}$ & 3 & $1017,7 \mathrm{a}$ \\
\hline Média geral & 895,3 & & $895,3 \alpha$ \\
\hline Test. (absoluta) & & $1122,9 \alpha$ \\
\hline CV (\%) & 23,75 \\
\hline
\end{tabular}

Médias seguidas pela mesma letra minúscula na coluna e maiúscula na linha, não diferem pelo teste de Tukey, a $5 \%$. As letras gregas diferentes indicam diferença a $5 \%$.
Tabela 7 - Condutividade elétrica das sementes de feijão nos períodos e ciclos de hidratação.

\begin{tabular}{|c|c|c|c|c|}
\hline \multirow{2}{*}{$\begin{array}{l}\text { Período de } \\
\text { hidratação }\end{array}$} & \multicolumn{4}{|c|}{ Ciclo de hidratação } \\
\hline & 1 ciclo & 2ciclos & 3ciclos & Média \\
\hline & \multicolumn{4}{|c|}{ 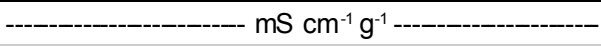 } \\
\hline $6 \mathrm{~h}$ & 94,46 aA & $79,65 \mathrm{aB}$ & $102,78 \mathrm{bA}$ & 92,30 \\
\hline $12 \mathrm{~h}$ & $85,58 \mathrm{abB}$ & $86,49 \mathrm{aB}$ & 126,38 aA & 99,48 \\
\hline $24 \mathrm{~h}$ & $80,90 \mathrm{bB}$ & $89,28 \mathrm{aAB}$ & $96,68 \mathrm{bA}$ & 88,95 \\
\hline Média & 86,98 & 85,14 & 108,61 & $93,57 \alpha$ \\
\hline Test. (absoluta) & & & & $95,20 \alpha$ \\
\hline CV (\%) & 7,82 & & & \\
\hline
\end{tabular}

Médias seguidas pela mesma letra minúscula na coluna e maiúscula na linha, não diferem pelo teste de Tukey, a $5 \%$. As letras gregas diferentes indicam diferença a $5 \%$.

Tabela 8 - Açúcares redutores da solução de embebição da condutividade elétrica das sementes de feijão nos períodos e ciclos de hidratação.

\begin{tabular}{lllll}
\hline \multirow{2}{*}{$\begin{array}{l}\text { Período de } \\
\text { hidratação }\end{array}$} & \multicolumn{4}{c}{ Ciclo de hidratação } \\
\cline { 2 - 5 } & 1 ciclo & 2ciclos & 3ciclos & Média \\
\hline 6h & 20,79 cAB & 22,55 aA & 13,23 aB & 18,86 \\
$12 \mathrm{~h}$ & 36,17 bA & 10,45 bB & 12,28 aB & 19,63 \\
$24 \mathrm{~h}$ & 51,35 aA & 12,32 bB & 13,04 aB & 25,57 \\
\hline Média & 36,10 & 15,10 & 12,85 & $21,35 \alpha$ \\
\hline Test. (absoluta) & & & & $13,85 \beta$ \\
\hline CV (\%) & 19,83 & & & \\
\hline
\end{tabular}

Médias seguidas pela mesma letra minúscula na coluna e maiúscula na linha, não diferem pelo teste de Tukey, a $5 \%$. As letras gregas diferentes indicam diferença a $5 \%$.

Tabela 9 - Lixiviados da solução de embebição das sementes de feijão nos diferentes períodos e ciclos de hidratação.

\begin{tabular}{|c|c|c|c|c|}
\hline \multicolumn{5}{|c|}{ Cálcio } \\
\hline \multirow{2}{*}{$\begin{array}{l}\text { Perío do de } \\
\text { hid ratação }\end{array}$} & \multicolumn{4}{|c|}{ Ciclos de hidratação } \\
\hline & 1 ciclo & 2ciclos & 3ciclos & Média \\
\hline \multicolumn{5}{|c|}{ 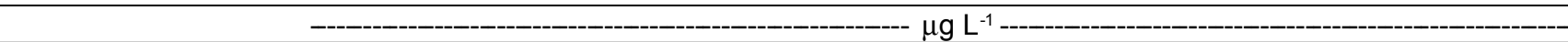 } \\
\hline $6 \mathrm{~h}$ & 1,49 aA & $1,68 \mathrm{aAB}$ & $1,88 \mathrm{bA}$ & 1,68 \\
\hline $12 \mathrm{~h}$ & $1,66 \mathrm{aB}$ & $1,58 \mathrm{aB}$ & $2,18 \mathrm{aA}$ & 1,81 \\
\hline $24 \mathrm{~h}$ & $1,47 \mathrm{aB}$ & $1,29 \mathrm{bB}$ & $2,06 a b A$ & 1,61 \\
\hline Média & 1,54 & 1,51 & 2,04 & $1,70 \alpha$ \\
\hline Test. (absoluta) & & & & $1,66 \alpha$ \\
\hline CV (\%) & 7,91 & & & \\
\hline \multicolumn{5}{|c|}{ |--------------------------------------------------' } \\
\hline $6 \mathrm{~h}$ & $11,00 \mathrm{aA}$ & 10,66 aA & $11,66 \mathrm{bA}$ & 11,11 \\
\hline $12 \mathrm{~h}$ & $9,33 \mathrm{aB}$ & $11,33 \mathrm{aB}$ & $17,00 \mathrm{aA}$ & 12,55 \\
\hline $24 \mathrm{~h}$ & $9,33 \mathrm{aB}$ & $10,67 \mathrm{aAB}$ & $12,66 \mathrm{bA}$ & 10,88 \\
\hline Média & 9,88 & 10,88 & 13,77 & $11,51 \alpha$ \\
\hline Test. (absoluta) & & & & $12,33 \alpha$ \\
\hline CV (\%) & 12,09 & & & \\
\hline \multicolumn{5}{|c|}{ - } \\
\hline $6 \mathrm{~h}$ & 209,66 aA & 189,00 aA & $218,66 \mathrm{bA}$ & 205,77 \\
\hline $12 \mathrm{~h}$ & $187,00 \mathrm{aB}$ & 191,66 aB & 253,33 aA & 210,66 \\
\hline $24 \mathrm{~h}$ & $177,66 \mathrm{aB}$ & $202,00 \mathrm{aAB}$ & $223,66 \mathrm{abA}$ & 201,11 \\
\hline Média & 191,44 & 194,22 & 231,88 & $205,84 \alpha$ \\
\hline Test. (absoluta) & & & & $210,33 \alpha$ \\
\hline CV (\%) & 7,73 & & & \\
\hline
\end{tabular}

Médias seguidas pela mesma letra minúscula na coluna e maiúscula na linha, não diferem pelo teste de Tukey, a $5 \%$. As letras gregas diferentes indicam diferença a $5 \%$. 


\section{CONCLUSÕES}

Sementes submetidas a tratamentos de hidratação-secagem, apresentam maior disponibilidade de proteínas de reserva, beneficiando o desempenho das sementes tratadas, em relação às testemunhas.

A perda de seletividade da membrana para açucares redutores, ocasionada pelos tratamentos de hidratação-secagem, não interfere na concentração de cátions e condutividade elétrica da solução ou na germinação e vigor das sementes tratadas.

\section{REFERÊNCIAS BIBLIOGRÁFICAS}

ABDEL-SAMAD, I.M.; PEARCE, R.S. Leaching of ions, organic molecules, and enzymes from seeds of peanut (Arachis hypogea L.) imbibing without testas or with intact testas. Journal of Experimental Botany, v.29, p.1471-1478, 1978.

ARAGÃO, C.A.; MORAIS, O.M.; LIMA, E.V.; LEMOS, L.B.; CAVARIANI, C.; NAKAGAWA, J. Efeito da hidratação seguido da secagem na qualidade fisiológica de sementes de feijão (Phaseolus vulgaris L.) Revista Brasileira de Sementes, v.21, p.180-186, 1999.

ASSOCIATION OF OFFICIAL SEED ANALYSIS. Seed vigour testing handbook. Lansing: AOSA, 1983. 88p.

BASU, R.N.; DASGUPTA, M. Control of seed deteriation by free radical controlling agents. Indian Journal of Experimental Biology, v.16, p.1070-1073, 1978.

BASU, R.N.; RUDRAPAL, A.L. Post-harvest seed physiology and seed invigoration treatments. In: INTERNATIONAL CONFERENCE ON FRONTIERS OF RESEARCH IN AGRICULTURE, Calcutta, 1982. Proceedings. Calcutta: Indian Statistical Institute Golden Jubilee, 1982. p.374-379.

BERRIE, A.M.M.; DRENNAN, D.S.H. The effect of hydration on seed germination. New Phytologist, v.70, p.135-142, 1971.

BRADFORD, M.M. A rapid and sensitive method for the quantitation of microgram quantities of protein utilizing the principle of protein-dye binding. Analytical Biochemistry, v.72, p.248-254, 1976.

BRASIL. Ministério da Agricultura e Reforma Agrária. Regras para análise de sementes. Brasília: SNAD; DNDV; CLAV, 1992. 365p.

DIAS, D.F.S.; BHÉRING, M.C.; GOMES, J.M.; SILVA, R.F. Efeito da hidratação-secagem na qualidade fisiológica de sementes de feijão-de-vagem (Phaseolus vulgaris L.) Revista Brasileira de Sementes, v.18, p.214-219, 1996.
HEGARTY, T.W. Seed activation and seed germination under moisture stress. New Phytologist, v.78, p.349-359, 1977.

HEGARTY, T.W. The physiology of seed hydration and dehydration, and the relation between water stress and the control of germination: A review. Plant Cell and Enviroment, v.1, p.101-119, 1978.

HEYDECKER, W.; HIGGING, J.; TURNER, Y.J. Invigoration of seeds. Seed Science and Technology, v.3, p.881-888, 1975.

ISHINO, K.; ORTEGA, M.L. Fractionation and characterization of major reserve proteins from seeds of Phaseolus vulgaris $\mathrm{L}$. Journal of Agricultural and Food Chemistry, v.23, p.529533, 1975.

LOOMIS, E.L.; SMITH, O.E. The effect of artificial ageing on the concentration of $\mathrm{Ca}, \mathrm{Mg}, \mathrm{Mn}, \mathrm{K}$, and $\mathrm{Cl}$ in imbibing cabbage seed. Journal of the American Society for Horticultural Science, v.105, p.647-650, 1980.

MAYER, A.M.; POLJAKOFF-MAYBER, A. The germination of seeds. Oxford: Pergamon Press, 1978. cap.2, p.10-20: Chemical composition of seeds.

MILLER, G.L. Use of dinitrosalicylic acid reagent for determination of reducing sugar. Analytical Biochemistry, v.31, p.426-428, 1959.

MOTTA, C.A.P.; SILVA, W.R. Efeito de hidratação e desidratação no desempenho fisiológico de sementes de trigo. Pesquisa Agropecuária Brasileira, v.32, p.379-390, 1997.

PAN, D.; BASU, R.N. Mid-storage and pre-sowing seed treatments for lettuce and carrot. Scientia Horticulturae, v.25, p.11-19, 1985.

PEARCE, R.S.; ABDEL-SAMAD, I.M. Change in fatty acid content of polar lipids during ageing of seeds of Peanut (Arachis hypogea L.) imbibing without testas or with intact testas. Journal of Experimental Botany, v.31, p.1283-1290, 1980.

PEÑALOZA, A.P.S; EIRA, M.T.S. Hydration-dehydration treatments on tomato seeds (Lycopersicon esculentum Mill.). Seed Science and Technology, v.21, p.309-316, 1993.

RUDRAPAL, D.; NAKAMURA, S. The effect of hydrationdehydration pretreatments on eggplant and radish seed viability and vigour. Seed Science and Technology, v.16, p.123-130, 1988.

VILLIERS, T.A.; EDGECUMBE, D.J. On the cause of seed deterioration in dry storage. Seed Science and Technology, v.3, p.761-774, 1975.

WILLIAMS, R.D. Moisture stress and hydration-dehydration effects on hemp Sesbania (Sesbania exaltata) seed germination. Weed Science, v.28, p.487-492,1980.

$\overline{\text { Recebido em } 30.10 .00}$ 